\title{
Work hours and turnover intention among hospital physicians in Taiwan: does income matter?
}

\author{
Yu-Hsuan Tsai ${ }^{1,2}$, Nicole Huang ${ }^{3}$, Li-Yin Chien ${ }^{4}$, Jen-Huai Chiang ${ }^{5}$ and Shu-Ti Chiou ${ }^{6,7,8^{*}}$
}

\begin{abstract}
Background: Physician shortage has become an urgent and critical challenge to many countries. According to the workforce dynamic model, long work hours may be one major pressure point to the attrition of physicians. Financial incentive is a common tool to human power retention. Therefore, this large-scale physician study investigated how pay satisfaction may influence the relationship between work hours and hospital physician's turnover intention.

Methods: Data were obtained from a nationwide survey of full-time hospital staff members working at 100 hospitals in Taiwan. The analysis sample comprised 2423 full-time physicians. Dependent variable was degree of the physicians' turnover intention to leave the current hospital. The pay satisfaction was assessed by physicians themselves. We employed ordinal logistic regression models to analyze the association between the number of work hours and turnover intention. To consider the cluster effect of hospitals, we used the "gllamm" command in the statistical software package Stata Version 12.1.

Results: The results show that 351 (14.5\%) of surveyed physicians reported strong intention to leave current hospital. The average work hours per week among hospital physicians was $59.8 \mathrm{~h}$. As expected, work hours exhibited an independent relationship with turnover intention. More importantly, pay satisfaction could not effectively moderate the positive relationship between work hours and intentions to leave current hospital.

Conclusions: The findings show that overtime work is prevalent among hospital physicians in Taiwan. Both the Taiwanese government and hospitals must take action to address the emerging problem of physician high turnover rate. Furthermore, hospitals should not consider relying solely on financial incentives to solve the problem. This study encouraged tackling work hour problem, which would lead to the possibility of solving high turnover intention among hospital physicians in Taiwan.
\end{abstract}

Keywords: Hospital physicians, Turnover intention, Work hours, Pay satisfaction

\section{Background}

Physician shortages are an emerging international concern [1-4]. More critically, there is no immediate solution to this problem. The workforce dynamic model, proposed by Sklar, suggests three phase of physician workforce dynamic and their various pressure points to which interventions can target [4]. Specifically, the attrition and outflow of physician threatens the functioning

\footnotetext{
* Correspondence: shuti.chiou@gmail.com

${ }^{6}$ Health Promotion Administration, Ministry of Health \& Welfare, Taipei, Taiwan

${ }^{7}$ School of Medicine, National Yang-Ming University, Taipei, Taiwan Full list of author information is available at the end of the article
}

of health care systems. High physician turnover can lead to an inadequate supply of health services, thereby compromising people's access to health care and endangering the quality of patient care and safety [5-7]. In addition, the adverse consequences of physician turnover may include financial loss, low patient satisfaction, and poor organizational practices [8].

Rapid changes in health care environments and increasing health care costs have led to great pressures on physicians. Hospital physicians may be particularly susceptible to these factors because of the nature and environment of their work. Compared with general practitioners, hospital 
physicians typically treat more patients with critical conditions, and they have a higher workload and lower job control. Furthermore, previous studies have indicated that psychosocial job stressors, high levels of distress, frequent sleep problems, heavy workloads, job dissatisfaction, and poor workplace relationships are plausible factors associated with high physician turnover [9-11]. Many of these work-related stress, distress, and dissatisfaction may be resulted partly from hospital physicians' long work hours $[12,13]$.

The situation may be worse in many newly developed countries. Several studies have indicated that the average work hours among physicians in Taiwan are greater than those of physicians in other developed countries [14, 15]. Although some studies are available in Asia or in Taiwan, these studies suffer from the methodological issues such as low response rates, poor generalizability, and a lack of detailed analyses on the relationship between work hours and turnover intention. Because physicians play a crucial role in ensuring a well-functioning health care system, many countries (e.g., France, Canada, and the United States) have attempted to restrict the maximum work hours of resident physicians [16]. However, in newly developed countries, understanding of these problems remains limited and few efforts have been made to regulate the work hours of hospital physicians, especially in attending physicians.

From a management perspective, a possible and intuitive approach to employee retention is to increase income. The National Health Insurance program in Taiwan is famous for low expenditure, high medical service usage, high coverage rate, and acceptable medical quality [17]. Low expenditure with high usage rate, combined with ageing problem and increased cost due to technology advancement, undoubtedly put great pressure on hospital's financial balance [18]. As a result, health professionals' income is always the target of controlling cost, including physicians. Recently in Taiwan, malpractice lawsuit, excessive workload, and unfair income are three most frequently mentioned causes of the physician shortage in hospitals. Whether elevating the pay satisfaction of physician is a useful approach to decrease the impact of long work hours on turnover rate is a critical question for hospital managers and health policy makers.

\section{Methods}

\section{Design and participants}

\section{Data source and study sample}

In this cross-sectional study, we adopted the nationwide hospital survey Needs Assessment Survey on Physical and Mental Health and Occupational Safety for Full-time Staff in Healthcare Workplace (Additional file 1) which was conducted by Bureau of Health Promotion in 2011. The structured questionnaire survey was developed to assess the health, health-related behaviors, and work conditions of hospital staffs in Taiwan. Work hours and turnover intention are two main dimensions assessed in this survey. Previous research has shown that the questionnaire has exhibited acceptable validity and introduced its sampling method clearly (Additional file 1). Among the 127 selected hospitals, 100 (78.7\%) agreed to participate in this survey, and all full-time staff members at these hospitals were requested to participate. The questionnaire was anonymous, and a return envelope was provided with each questionnaire. Hospital staffs were requested to return the completed questionnaires in a sealed envelope to collecting sites at the hospitals. We distributed 98,817 questionnaires from May 2011 to July 2011, and 70,622 (71.5\%) validated questionnaires were returned. Among those who returned their questionnaires, 4538 respondents reported that they were physicians. After we excluded responses with incomplete information (678 people) and those below 35 years old (1437 people), the final sample in our study comprised responses from 2423 attending physicians. For those below 35 years old, they are very likely still under trainee. After accomplishing trainee, it is reasonable to change to other hospitals to pursue their new medical lives. To avoid overestimating the meaning of intention to leave current hospital as the willing of turnover, we only analyzed the physician group above 35 years old. Furthermore, following previous studies, we chose to focus on physicians' intention to withdraw, instead of actual turnover, as the dependent variable for several considerations [11, 19]. First, the cross-sectional nature of the survey prevented the measurement of physicians' actual turnover from practice. Second, previous studies have shown turnover intention is a reliable predictor of actual turnover $[20,21]$. The study protocol was approved by the institutional review board at the Bureau of Health Promotion prior to distributing the survey (BHP investigation number 0990800708).

\section{Measurements \\ Dependent variable}

Turnover intention was assessed using one question ("What is the likelihood that you will leave your current hospital?". The responses were measured using a 5-point Likert scale ranging from 1 (none) to 5 (very strong). We classified turnover intention as mild (i.e., physicians who answered none or mild), moderate (i.e., physicians who answered moderate), or strong (physicians who answered strong or very strong).

\section{Independent variable and moderating variable}

The main independent variable was the number of work hours, which was measured using the survey item "Please recall how many hours you worked in the last week". According to Taiwan Labor Standards Act, the normal 
weekly work hours shall not exceed $48 \mathrm{~h}$, and the overtime weekly work hours shall not exceed 60 h [22]. Physicians in Taiwan are not considered laborers; thus, the Labor Standards Act does not apply to this profession. No legislation exists to regulate hospital physicians' work hours, so the proposed reference of an 88-h maximum for residents' work hours per week by the American ACGME (The Accreditation Council for Graduate Medical Education) was also adopted as one cut point [23]. Based on those cut points, we categorized the sample into five groups $(<49,49-59,60-88$, and $>88 \mathrm{~h})$ to further evaluate the impact of work hours on turnover intention.

The moderating variable considered in this study was pay satisfaction, which was assessed by one question ("Do you think it is reasonable for your current work pay?". The responses were measured using a 5-point Likert scale ranging from 1 (very unreasonable) to 5 (very reasonable). We classified pay satisfaction as bad (i.e., physicians who answered very unreasonable or little unreasonable), moderate (i.e., physicians who answered moderate), or good (physicians who answered not bad or very reasonable).

\section{Control variables}

In the analyses, we also included sociodemographic variables (age, gender, and marital status) and work characteristics variables (seniority at current hospital, clinical setting, supervisor position, accredited hospital level, hospital ownership, and health promoting hospital $(\mathrm{HPH})$ status). Furthermore, we subsequently included health status and job satisfaction as control variables to adjust their impact on the relationship between work hours and turnover intention. Self-rated health status was separately categorized into three groups (good, moderate, and bad), and job satisfaction was divided into two groups (good and bad).

\section{Statistical analyses}

We employed ordinal logistic regression models to analyze the association between the number of work hours and turnover intention. This method is suitable for dependent variables with multiple ordered response categories, and we verified the appropriateness of using this model, which means the relationship between any two pairs of outcome groups is statistically the same. To consider the cluster effect of hospitals, we used the "gllamm" command in the statistical software package Stata Version 12.1(StataCorp, 4905 Lakeway Drive College Station, Texas 77845-4512 USA), which can estimate generalized linear latent and mixed models. First, multivariable regression was applied to determine the relationship between work hours and turnover intention by adjusting the sociodemographic and work characteristics variables (Model 1). Next, we analyzed the association between work hours and turnover intention by incorporating health status, pay satisfaction, and job satisfaction into the models (Model 2). Finally, to evaluate whether pay satisfaction moderated the relationship between work hours and turnover intention, we conducted stratification analyses based on the level of pay satisfaction.

\section{Results}

Table 1 lists the distribution of the physicians' characteristics and weekly work hours, showing that 351 (14.5\%) of the surveyed physicians reported strong intention to leave their current hospital. There were up to 727 (30.0\%) physicians rating pay satisfaction as bad. The average weekly work hours among Taiwan hospital physicians was 59.8 (19.9). Regarding the categories for the number of work hours per week, 1102 (45.5\%) of the physicians worked more than $60 \mathrm{~h}$, and 207 (8.5\%) physicians worked more than $88 \mathrm{~h}$. Longer work hours were associated with a stronger intention to leave a hospital. Additionally, the number of work hours decreased as age increased. On average, women worked $6 \mathrm{~h}$ less per week than their male counterparts. Those who were working in surgery or delivery rooms, emergency or intensive care unit reported a relatively much higher number of weekly work hours as 66.0 and 65.0, respectively. Physicians who were employed at medical centers reported working much longer hours than their counterparts in regional or district hospitals as $64.4 \mathrm{~h}$ per week. In addition, as average weekly work hours increased, self-rated health status, pay satisfaction, and job satisfaction deteriorated significantly. Table 2 shows that longer work hours and lower pay satisfaction were both related to higher turnover intention to leave current hospital, and the impact was statistically significant $(P$ value $<0.001)$ and substantial.

Table 3 shows the association between work hours and intention to leave the current hospital. After we controlled for other variables, work hours exhibited a independent relationship with turnover intention. After adjusting for socio-demographic variables and work characteristics (Model 1), our results indicated that in comparison with physicians who worked less than $49 \mathrm{~h}$ per week, those who worked 60-88 h (OR, 1.40; 95\% CI, 1.14-1.72) and more than $88 \mathrm{~h}$ (OR, 2.09; 95\% CI, 1.52-2.87) had significantly stronger intentions to leave their current hospital. After we added health status, pay satisfaction, and job satisfaction into the model (Model 2 ), the positive relationship between work hours and intention to leave their current hospital persisted, although the magnitude of the effects reduced moderately for both the $60-88 \mathrm{~h}$ group (OR, 1.22; 95\% CI, $0.98-1.51$ ) and the more than $88 \mathrm{~h}$ group (OR, 1.53; 95\% CI, 1.10-2.13). Furthermore, in multivariate analysis, young physicians, moderate seniority at current 
Table 1 Physician Characteristics and Work Hours Distribution

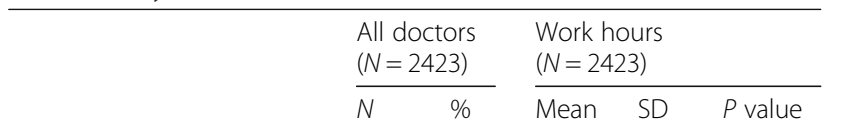

Dependent Variables

Leave hospital

mild

moderate

strong

Independent Variables

Work hours

$<=48$

$49-59$

60-88

$>=89$

Age

35-49

$>=50$

Gender

male

female

Marital status

unmarried

married

Others

Seniority at current hospital

$<=1$ year

2-5 years

$>5$ years

Clinical setting (1)

others

surgery or delivery room

Clinical setting (2)

others

emergency or ICU

Supervisor

supervisor

on-Supervisor

Accredited hospital level

district hospital

medical center

Hospital ownership

public hospital

private hospital

$\begin{array}{llll} & & & \\ 1328 & 54.8 & 58.3 & 19.3 \\ 744 & 30.7 & 60.1 & 19.3 \\ 351 & 14.5 & 64.9 & 22.3\end{array}$

$P<0.001$

(1)

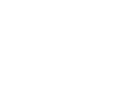

Chork hours

$P<0.001$

19.8

$\begin{array}{llll}397 & 16.4 & 54.7 & 19.4\end{array}$

$\begin{array}{llll}213 & 8.8 & 58.9 & 19.8\end{array}$

$\begin{array}{llll}2136 & 88.2 & 59.7 & 19.5\end{array}$

$\begin{array}{llll}74 & 3.1 & 65.1 & 28.3\end{array}$

$\begin{array}{llll}210 & 8.7 \quad 59.4 & 22.0\end{array}$

$\begin{array}{llll}533 & 22.0 & 61.1 & 20.4\end{array}$

$\begin{array}{llll}1680 & 69.3 & 59.5 & 19.4\end{array}$

$\begin{array}{llll}624 & 67.0 & 56.8 & 17.8\end{array}$

$\begin{array}{llll}799 & 33.0 & 66.0 & 22.3\end{array}$

$P<0.001$

$\begin{array}{llll}1652 & 68.2 & 57.4 & 18.6\end{array}$

$\begin{array}{llll}771 & 31.8 & 65.0 & 21.5\end{array}$

$\begin{array}{llll}879 & 36.3 & 60.5 & 19.1\end{array}$

$\begin{array}{llll}1544 & 63.7 & 59.5 & 20.3\end{array}$

$\begin{array}{llll}159 & 6.6 & 54.4 & 16.3\end{array}$

$\begin{array}{llll}1711 & 70.6 & 58.8 & 19.5\end{array}$

$\begin{array}{llll}553 & 22.8 & 64.4 & 21.2\end{array}$

$\begin{array}{llll}901 & 37.2 & 58.4 & 18.7\end{array}$

$\begin{array}{llll}1522 & 62.8 & 60.6 & 20.5\end{array}$
Health Promoting Hospital

$(\mathrm{HPH})$ status

(Continued)

\begin{tabular}{lccccc}
\hline $\begin{array}{l}\text { Health Promoting Hospital } \\
\text { (HPH) status }\end{array}$ & & & & & $P=0.396$ \\
Non-HPH & 1057 & 43.6 & 60.4 & 20.0 & \\
HPH & 805 & 33.2 & 59.4 & 19.6 & \\
Exemplary HPH & 561 & 23.2 & 59.2 & 20.0 & \\
Health status & & & & & $P<0.001$ \\
good & 510 & 21.1 & 57.6 & 19.0 & \\
moderate & 1471 & 60.7 & 59.8 & 19.7 & \\
bad & 442 & 18.2 & 62.6 & 21.0 & \\
$\begin{array}{l}\text { Pay satisfaction } \\
\text { good }\end{array}$ & & & & & $P<0.001$ \\
moderate & 452 & 18.7 & 56.1 & 16.8 & \\
bad & 1244 & 51.3 & 58.8 & 19.1 & \\
Job satisfaction & 727 & 30.0 & 63.8 & 22.2 & \\
$\quad$ good & & & & & $P<0.001$ \\
bad & 1804 & 74.5 & 58.3 & 18.6 & \\
\hline
\end{tabular}

$P=0.058$

$P=0.247$

$P=0.231$

$P<0.001$

$P=0.008$

$P<0.001$

hospital ( $2-5$ years), poor self-perceived health status, pay dissatisfaction, and job dissatisfaction were significant predictors of strong intention to leave current hospital.

To determine whether pay satisfaction moderated the association between work hours and turnover intention, we conducted stratification analyses (Table 4). The result indicated that among those who perceive their income as good or bad, the relationship between work hours and turnover intention disappeared. However, for those who stated moderate pay satisfaction, which comprised the majority of physicians (51.3\%), work hours remained strong independent relationship with turnover intention. Those who worked $60-88$ h (OR, 1.57; 95\% CI, 1.15-2.13) and more than $88 \mathrm{~h}(\mathrm{OR}, 2.00$; 95\% CI, 1.21-3.32) had significantly stronger intentions to leave their current hospital comparing with physicians who worked less than $49 \mathrm{~h}$ per week. However, the overall interaction P value of pay satisfaction and work hours did not reach the level of statistical significance $(P$ value $=0.447)$.

\section{Discussion}

This is the first article to directly analyze the effect of work hours on turnover intention, and also put pay satisfaction into consideration to estimate the possible moderating effect. There are three interesting findings. First, the average work hours among hospital physicians who are above 35 years old in Taiwan was 59.8 (19.9) hours per week, which was considerably higher than that of physicians in United States (49.6 h per week for nonresident physicians) [24]. More importantly, 214 (8.6\%) of the surveyed physicians worked more than $88 \mathrm{~h}$ per week. Second, a clear independent relationship was 
Table $\mathbf{2}$ Crude ratio of intention to leave hospital with work hours and pay satisfaction

\begin{tabular}{|c|c|c|c|c|c|}
\hline & \multicolumn{5}{|c|}{ Intention to leave current hospital $(N=2423)$} \\
\hline & Mild & Moderate & Strong & Total & $P$ value \\
\hline Work hours & & & & & $P<0.001$ \\
\hline \multicolumn{6}{|l|}{$<=48$} \\
\hline N & 435 & 207 & 76 & 718 & \\
\hline$\%$ & 60.6 & 28.8 & 10.6 & 100.0 & \\
\hline \multicolumn{6}{|l|}{$49-59$} \\
\hline N & 331 & 183 & 89 & 603 & \\
\hline$\%$ & 54.9 & 30.4 & 14.8 & 100.0 & \\
\hline \multicolumn{6}{|l|}{$60-88$} \\
\hline N & 473 & 286 & 136 & 895 & \\
\hline$\%$ & 52.9 & 32.0 & 15.2 & 100.0 & \\
\hline \multicolumn{6}{|l|}{$>=89$} \\
\hline N & 89 & 68 & 50 & 207 & \\
\hline$\%$ & 43.0 & 32.9 & 24.2 & 100.0 & \\
\hline Pay satisfaction & & & & & $P<0.001$ \\
\hline \multicolumn{6}{|l|}{ Good } \\
\hline$N$ & 335 & 89 & 28 & 452 & \\
\hline$\%$ & 74.1 & 19.7 & 6.2 & 100.0 & \\
\hline \multicolumn{6}{|l|}{ Moderate } \\
\hline$N$ & 737 & 409 & 98 & 1244 & \\
\hline$\%$ & 59.2 & 32.9 & 7.9 & 100.0 & \\
\hline \multicolumn{6}{|l|}{ Bad } \\
\hline$N$ & 256 & 246 & 225 & 727 & \\
\hline$\%$ & 35.2 & 33.8 & 31.0 & 100.0 & \\
\hline
\end{tabular}

observed between work hours and turnover intention. These findings not only raise serious concerns regarding the health and wellbeing of physicians but also indicate that overtime work may increase physicians' intentions to leave their current practice; thus, adding unnecessary administrative cost and more critically, endangering the continuity of patient care. The physician shortage problem in the hospital sector may threaten the function of the health care system. Unlike other factors associated with physicians' turnover intentions (e.g., work stress, job satisfaction, etc.), work hours is a tangible and actionable factor. By building a reasonable work hour regulation, we can improve the wellbeing of physicians and diminish the possibility of leaving current practice setting.

Third, we know that even though financial incentive plays an important role in retaining physicians, it still cannot effectively moderate the adverse effect of long work hours on turnover intention. Similar results have been proposed by previous studies. One cross-sectional study in Ghana revealed that the dimensions of motivation and job satisfaction significantly associated with turnover intention included career development, workload, management, organizational commitment, and burnout, but not remuneration [25]. Another article conducted in England to retain the general practitioner workforce showed that reduced intensity and volume of workload were more important than incentive payment [26]. A review article to survey incentives for retaining health workers also documented financial incentives alone would exert limited effort. Working conditions, supervision and management, and education and training opportunities were also important and needed to be addressed together [27]. As a result, hospital managers and government should not overlook the influential role of work hours. Money cannot solve everything, and there are still root causes which drive the turnover intention of physician, such as long work hours. Taking action on improving the overload of work can assist elevating the wellbeing of physicians, and resulting in mitigating turnover intention, which assure the well function of health system.

However, there were some limitations in this study. First, because this was a cross-sectional study, we were unable to ascertain the causal relationship between work hours and turnover intention, which could be addressed by future longitudinal studies. Second, because of data limitations, some relevant information, such as the physicians' rank (intern, resident, fellow, or attending physician) or specialty were unavailable, thus preventing detailed analyses. However, we have tried to use the variables of age and clinical settings to offer more information. Third, because we were not assured the exact number of physicians who attained the questionnaire, it's impossible to calculate the specific physicians' response rate in this study. Forth, work hours were self-reported and based on recall, which may have resulted in the figures being over-reported or under-reported because of perceived differences related to work. If the reporting is non-differential, the effects of work hours may be stronger than we observed. Besides, some points require further discussion. Although we used weekly work hours as our primary independent variable, the concept of work hours should be refined to elucidate the turnover problem further. For example, the number of work hours is not necessarily representative of work intensity [28]. Other variables (e.g., job control and work schedule flexibility) may also affect the psychological health of physicians [29]. The stress feeling at work, the interruptions and other variables regarding work situation was incomplete, thus, hinder further understanding about the true root of work hour issue. Moreover, the intentions to retire, take a career break, or reduce clinical hours of work are important questions about physician workforce which were lack in the survey. Finally, although we sought to include as many as possible 
Table 3 Work hours and Intentions to leave current hospital

\begin{tabular}{|c|c|c|c|c|c|c|}
\hline & \multicolumn{6}{|c|}{ Intentions to leave current hospital $(N=2423)$} \\
\hline & \multicolumn{2}{|c|}{ Simple Ordinal Logistic Regression } & \multicolumn{2}{|c|}{ Model 1} & \multicolumn{2}{|l|}{ Model 2} \\
\hline & $\overline{\mathrm{OR}}$ & 95\% C.I. & $\overline{\mathrm{OR}}$ & 95\% C.I. & $\overline{O R}$ & 95\% C.I. \\
\hline \multicolumn{7}{|l|}{ Work hours (REF $=<=48$ ) } \\
\hline $49-59$ & $1.28^{*}$ & $1.03-1.59$ & $1.31^{*}$ & $1.05-1.63$ & 1.21 & $0.96-1.52$ \\
\hline $60-88$ & $1.40^{* *}$ & $1.15-1.71$ & $1.40^{* *}$ & $1.14-1.72$ & 1.22 & $0.98-1.51$ \\
\hline$>-89$ & $2.29^{* * *}$ & $1.69-3.11$ & $2.09^{* * *}$ & $1.52-2.87$ & $1.53^{*}$ & $1.10-2.13$ \\
\hline \multicolumn{7}{|l|}{ Age $(R E F=>=50)$} \\
\hline $35-49$ & $2.02^{* * *}$ & $1.68-2.42$ & $1.85^{* * *}$ & $1.53-2.23$ & $1.73^{* * *}$ & $1.42-2.11$ \\
\hline \multicolumn{7}{|l|}{ Gender $($ REF $=$ male $)$} \\
\hline Female & 1.01 & $0.82-1.25$ & 0.98 & $0.78-1.22$ & 1.08 & $0.85-1.36$ \\
\hline \multicolumn{7}{|c|}{ Marital status $(\mathrm{REF}=$ unmarried $)$} \\
\hline Married & $0.75^{*}$ & $0.57-0.98$ & 0.86 & $0.65-1.14$ & 1.19 & $0.88-1.60$ \\
\hline Others & 1.11 & $0.66-1.86$ & 1.30 & $0.77-2.20$ & 1.42 & $0.82-2.46$ \\
\hline \multicolumn{7}{|c|}{ Seniority at current hospital (REF $=<=1$ year) } \\
\hline 2-5 years & $1.68^{* *}$ & $1.22-2.32$ & $1.65^{* *}$ & $1.19-2.29$ & $1.49^{*}$ & $1.06-2.10$ \\
\hline$>5$ years & 1.30 & $0.97-1.74$ & $1.51^{* *}$ & $1.11-2.05$ & 1.36 & $0.99-1.87$ \\
\hline \multicolumn{7}{|c|}{ Clinical setting (1) (REF = others) } \\
\hline Surgery or delivery room & 1.05 & $0.88-1.24$ & 0.94 & $0.79-1.13$ & 0.91 & $0.75-1.09$ \\
\hline \multicolumn{7}{|c|}{ Clinical setting (2) (REF = others) } \\
\hline Emergency or ICU & $1.36^{* * *}$ & $1.15-1.61$ & 1.16 & $0.97-1.39$ & 0.97 & $0.81-1.17$ \\
\hline \multicolumn{7}{|l|}{ Supervisor (REF = supervisor) } \\
\hline Non-supervisor & $1.45^{* * *}$ & $1.23-1.71$ & $1.31^{* *}$ & $1.10-1.57$ & 1.09 & $0.91-1.31$ \\
\hline \multicolumn{7}{|c|}{ Accredited hospital level (REF = district hospital) } \\
\hline Regional hospital & 1.07 & $0.72-1.57$ & 1.03 & $0.69-1.52$ & 1.12 & $0.76-1.66$ \\
\hline Medical center & 0.97 & $0.61-1.53$ & 0.95 & $0.59-1.52$ & 0.93 & $0.58-1.47$ \\
\hline \multicolumn{7}{|c|}{ Hospital ownership (REF = public) } \\
\hline Private hospital & $0.80^{*}$ & $0.65-0.99$ & 0.82 & $0.66-1.03$ & 0.81 & $0.65-1.01$ \\
\hline \multicolumn{7}{|l|}{ HPH status (REF $=$ Non- $\mathrm{HPH})$} \\
\hline $\mathrm{HPH}$ & 1.19 & $0.94-1.51$ & 1.18 & $0.93-1.51$ & 1.03 & $0.81-1.30$ \\
\hline Exemplary HPH & 0.95 & $0.71-1.26$ & 0.96 & $0.72-1.28$ & 0.83 & $0.63-1.09$ \\
\hline \multicolumn{7}{|l|}{ Health status (REF = good) } \\
\hline Moderate & $1.70^{* * *}$ & $1.37-2.09$ & & & 1.24 & $0.99-1.55$ \\
\hline Bad & $3.15^{* * *}$ & $2.43-4.08$ & & & $1.59^{* *}$ & $1.21-2.10$ \\
\hline \multicolumn{7}{|l|}{ Pay $($ REF = good $)$} \\
\hline Moderate & $1.87^{* * *}$ & $1.47-2.38$ & & & $1.51^{* *}$ & $1.18-1.94$ \\
\hline Bad & $6.33^{* * *}$ & $4.88-8.21$ & & & $2.61^{* * *}$ & $1.96-3.48$ \\
\hline \multicolumn{7}{|l|}{ Job satisfaction (REF $=$ good) } \\
\hline Bad & $7.34^{* * *}$ & $6.05-8.91$ & & & $4.69^{* * *}$ & $3.76-5.85$ \\
\hline
\end{tabular}

$\mathrm{HPH}$ : Health Promoting Hospital

${ }^{*} P<0.05{ }^{*} P<0.01{ }^{* * *} P<0.001$

confounding variables in the analyses according to literature review, there may still be other factors that need to be explored further. For future studies, postquestionnaire focus groups or individual one-to-one interviews would be useful to get a more in-depth understanding of the factors responsible for employment unhappiness.

In order to implement the findings of this study, we may need to rethink of the medical system. If some physicians quit form the job due to long work hours, 
Table 4 Pay satisfaction stratification analysis

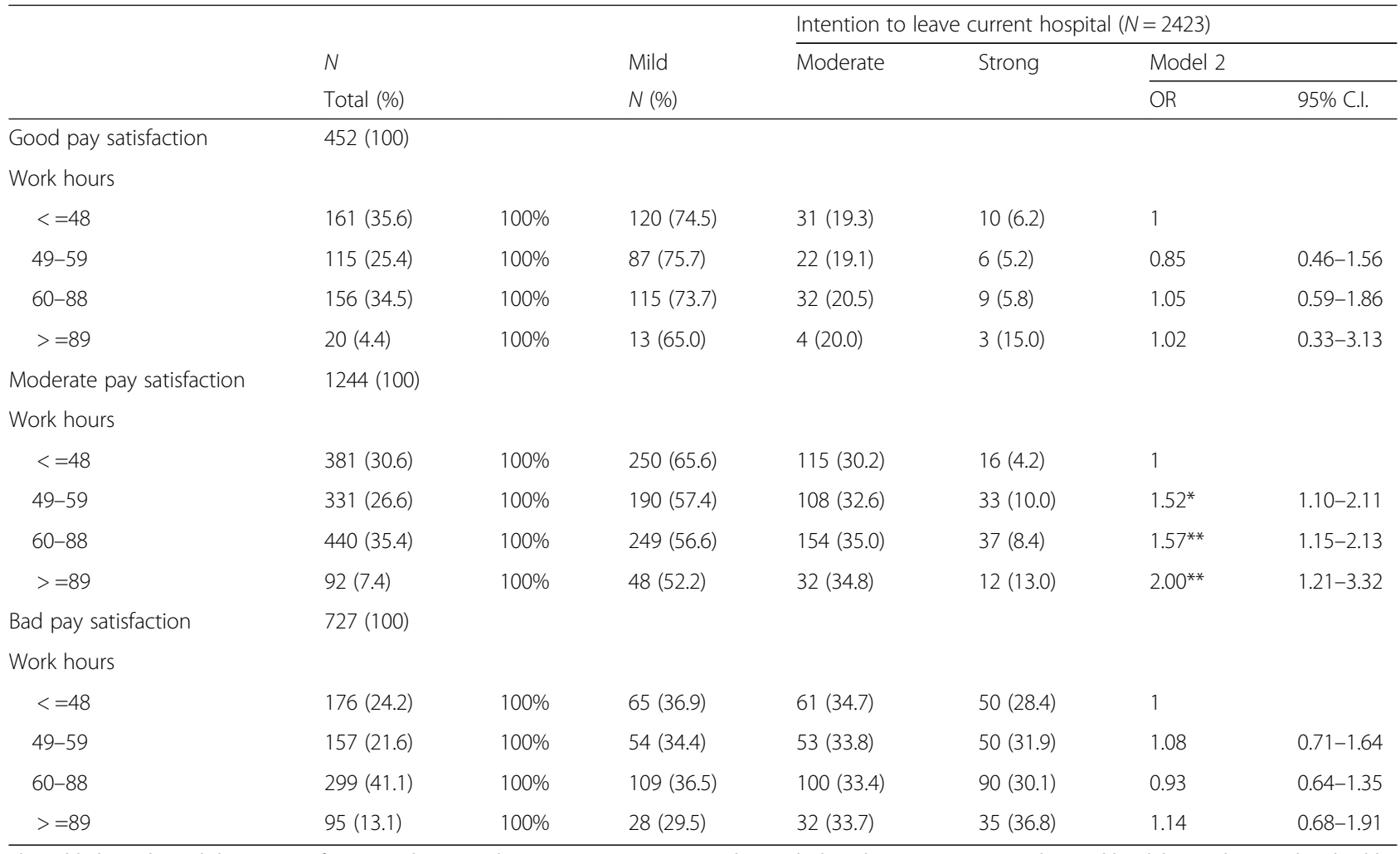

This table has adjusted the impact of age, gender, marital status, seniority at current hospital, clinical setting, supervisor, hospital level, hospital ownership, health promoting hospital status, health status, and job satisfaction. (2) The interaction $\mathrm{P}$ value is 0.447 , which was far away from achieving statistically significant level ${ }^{*} P<0.05{ }^{* *} P<0.01$

then those who stay in position will encounter more work hours, and thus lead to stronger intention of leaving their hospital. From the results of this article, we should break up the pernicious circle between long work hours and turnover intention. However, if cutting number of hours each physician does during a week is the proposed solution, then more physicians will presumably be needed to fulfill the same workload as now. Some plausible methods should be attempted to solve the possible workforce shortage problem. For instance, task shifting to replacement medical staff, such as enhancing the role and increasing the number of nurse practitioners or physician assistants may be suitable. Developing more effective information systems may help physicians to work more efficiently during their work hour. Strengthening the ability of primary care system and spreading the ideas of integrated medicine will also reduce the workload of hospital specialty physicians. Based on above method or other innovative solutions, we can reduce physician's long work hours without necessarily increasing the total number of physicians.

\section{Conclusions}

In this study, we conducted a large-scale survey of hospital physicians. The sample comprised 2423 physicians working at 100 hospitals in Taiwan, assuring good generalizability of the study. The medical centers and regional hospitals where physician shortages were the most serious in Taiwan were included in the sample. The number of total hospital physicians working in Taiwan in 2011 was 24,552, and this study included $9.9 \%$ of them to conduct analyses [30]. The sample size of 2423 physicians ensured high statistical power, not only in determining the significant effects of work hours on turnover intentions but also in examining whether pay satisfaction moderates this association. The findings show that overtime work is prevalent among hospital physicians in Taiwan. Both the Taiwanese government and hospitals must take action to address the emerging problem of physician high turnover rate. Regularly assessing physicians' work conditions (e.g., work hours), and limiting excess work hours may be suitable policy tools. Furthermore, hospitals should not consider relying solely on financial incentives to solve the problem. There was a clear need to face the overload work hours of hospital physicians. Although it may be difficult and challenging, this study encouraged tackling work hour problem, which would lead to the possibility of solving high turnover intention among hospital physicians in Taiwan. 


\section{Additional file}

Additional file 1: A preliminary English version of the questionnaire "Needs Assessment Survey on Physical and Mental Health and Occupational Safety for Full-time Staff in Healthcare Workplace". (PDF 312 kb)

\section{Acknowledgements}

The authors would like to thank Health Promotion Administration for providing the data and sponsorship for this research (BHP 1020210251). The authors also appreciate the support of the Ministry of Science and Technology (former National Science Council), Taiwan (grant number: 104-2314-B-010-007-MY3).

\section{Funding}

This work was supported by Health Promotion Administration, Ministry of Health and Welfare, Taipei, Taiwan; and by the Ministry of Science and Technology (former National Science Council), Taiwan (grant number: 104-2314-B-010-007-MY3).

\section{Availability of data and materials}

We won't provide the original data due to the ownership of the database is Health Promotion Administration, Ministry of Health \& Welfare, Taiwan. We also guarenteed to our participants that the reply would only be used for analysis and publication. The questionnaire is originally a Chinese version. We have provided the preliminary English version "Needs Assessment Survey on Physical and Mental Health and Occupational Safety for Full-time Staff in Healthcare Workplace" as supplement material (Additional file 1). Please contact the corresponding author (Shu-Ti Chiou) to request further information on the Questionnaire (Additional file 1) and secure permission to use the Questionnaire.

\section{Authors' contributions}

YHT carried out the statistical analysis, drafted the manuscript, and participated in the design of this study. Dr. STC carried out the data collection, participated in the design of this study, and helped to draft the manuscript. Dr. NH participated in the design and coordination of this study, and helped to do critical revisions of manuscript. Dr. LYC helped to do critical revisions of manuscript and and refined the conception of this study. Mr. JHC carried out the data compilation, and helped to perform statistical analysis. All authors read and approved the final manuscript.

\section{Competing interests}

The authors declare that they have no competing interests.

\section{Consent for publication}

All participants were spontaneously willing to participate in this study, and all of them finished the anonymous questionnaires. We also obtained the consent of them to publish the analysis results of this questionnaire.

\section{Ethics approval and consent to participate}

This study had ethics approval and consent from Bureau of Health Promotion, BHP investigation number 0990800708.

\section{Author details \\ ${ }^{1}$ International Health Program, School of Medicine, National Yang-Ming University, Taipei, Taiwan. ${ }^{2}$ Kaohsiung Veterans General Hospital, Kaohsiung, Taiwan. ${ }^{3}$ Institute of Hospital and Health Care Administration, National Yang-Ming University, Taipei, Taiwan. ${ }^{4}$ Institute of Community Health Care, National Yang-Ming University, Taipei, Taiwan. ${ }^{5}$ Research \& Development, Health Promotion Administration, Ministry of Health and Welfare, Taipei, Taiwan. ${ }^{6}$ Health Promotion Administration, Ministry of Health \& Welfare, Taipei, Taiwan. ${ }^{7}$ School of Medicine, National Yang-Ming University, Taipei, Taiwan. ${ }^{8}$ Taoyuan General Hospital, Ministry of Health \& Welfare, 1492, Jhongshan Rd., Taoyuan District, Taoyuan City 33004, Taiwan.}

Received: 4 March 2016 Accepted: 9 November 2016 Published online: 21 November 2016

\section{References}

1. Sheldon GF, Ricketts TC, Charles A, King J, Fraher EP, Meyer A. The global health workforce shortage: role of surgeons and other providers. Adv Surg. 2008;42:63-85.
2. Toyabe S. Trend in geographic distribution of physicians in Japan. Int J Equity Health. 2009;8:5.

3. Iglehart JK. A New Day Dawns For Workforce Redesign. Health Affairs. 2013;32:1870.

4. Sklar DP. How Many Doctors Will We Need? A Special Issue on the Physician Workforce. Academic Medicine. 2013;88:1785-7.

5. Buchbinder SB, Wilson M, Melick CF, Powe NR. Estimates of costs of primary care physician turnover. Am J Manag Care. 1999;5:1431-8.

6. Plomondon ME, Magid DJ, Steiner JF, et al. Primary care provider turnover and quality in managed care organizations. Am J Manag Care. 2007;13:465-72.

7. Firth-Cozens J, Greenhalgh J. Doctors' perceptions of the links between stress and lowered clinical care. Soc Sci Med. 1997:44:1017-22.

8. Misra-Hebert AD, Kay R, Stoller JK. A review of physician turnover: rates, causes, and consequences. Am J Med Qual. 2004;19:56-66.

9. Heponiemi T, Kouvonen A, Vanska J, et al. The association of distress and sleeping problems with physicians' intentions to change profession: the moderating effect of job control. J Occup Health Psychol. 2009;14:365-73.

10. Kankaanranta T, Nummi T, Vainiomaki J, et al. The role of job satisfaction, job dissatisfaction and demographic factors on physicians' intentions to switch work sector from public to private. Health Policy. 2007:83:50-64.

11. Masselink LE, Lee SY, Konrad TR. Workplace relational factors and physicians' intention to withdraw from practice. Health Care Manage Rev. 2008;33:178-87.

12. Baldwin Jr DC, Daugherty SR, Tsai R, Scotti Jr MJ. A national survey of residents' self-reported work hours: thinking beyond specialty. Acad Med. 2003;78:1154-63.

13. Ayas NT, Barger LK, Cade BE, et al. Extended work duration and the risk of self-reported percutaneous injuries in interns. JAMA. 2006;296:1055-62.

14. Fang Mao C.-J. T., Ya-Yuarn Hsu, Chin-Chi Mao, Shih-Yi Lu, Mei-Lien Chen. A Field Study of Overtime Work and Shift Work for Hospital Employees in Taiwan. J Occup Safety Health. 2011;19:233-246.

15. Ming-Chin Yang Y.-F. L., Shi-Lunwei. An Analysis of the Work Hours and Related Factors Associated with Attending Physicians and Residents in Teaching Hospitals. J Med Education. 2007;11:222-233.

16. Woodrow SI, Segouin C, Armbruster J, Hamstra SJ, Hodges B. Duty hours reforms in the United States, France, and Canada: is it time to refocus our attention on education? Acad Med. 2006:81:1045-51.

17. Wen CP, Tsai SP, Chung WS. A 10-year experience with universal health insurance in Taiwan: measuring changes in health and health disparity. Ann Intern Med. 2008:148:258-67.

18. Huang SK, Tsai SL, Hsu MT. Ensuring the sustainability of the Taiwan National Health Insurance. J Formos Med Assoc. 2014;113:1-2.

19. Williams ES, Konrad TR, Scheckler WE, Pathman DE, Linzer M, McMurray JE, et al. Understanding physicians' intentions to withdraw from practice: The role of job satisfaction, job stress, mental and physical health. Health Care Manag Review. 2001;26(1):7-19.

20. Buchbinder SB, Wilson M, Melick CF, Powe NR. Primary care physician job satisfaction and turnover. Am J Managed Care. 2001;7(7):701-13.

21. Griffeth RW, Hom PW, Gaertner S. A metaanalysis of antecedents and correlates of employee turnover: Update, moderator tests, and research implications for the next millennium. J Manag. 2000;26(3):463-88.

22. Council of Labor Affairs. Labor Standards Act (modified). 2015. http://law.moj. gov.tw/Eng/LawClass/LawAll.aspx?PCode=N0030001. Accessed 12 Nov 2016.

23. Accreditation Council for Graduate Medical Education (ACGME) Chicago. The ACGME 2011 Duty Hour Standard: Enhancing Quality of Care, Supervision and Resident Professional Development. https://www.acgme. org/Portals/O/PDFs/jgme-monograph[1].pdf. Accessed 27 Aug 2016.

24. Staiger DO, Auerbach DI, Buerhaus PI. Trends in the work hours of physicians in the United States. JAMA. 2010;303:747-53.

25. Bonenberger M, Aikins M, Akweongo P, Wyss K. The effects of health worker motivation and job satisfaction on turnover intention in Ghana: a crosssectional study. Human Resources Health. 2014:12:43.

26. Dale J, Potter R, Owen K, Parsons N, Realpe A, Leach J. Retaining the general practitioner workforce in England: what matters to GPs? A crosssectional study. BMC Family Practice. 2015;16:140.

27. Henderson LN, Tulloch J. Incentives for retaining and motivating health workers in Pacific and Asian countries. Human Resources Health. 2008;6:18.

28. Chen HF, Lee $\mathrm{CH}$, Chang RE. Workload of attending physicians at an academic center in Taiwan. J Chin Med Assoc. 2010;73:425-30.

29. Taylor DM, Pallant JF, Crook HD, Cameron PA. The psychological health of emergency physicians in Australasia. Emerg Med Australas. 2004;16:21-7.

30. Taiwan Medical Association. Physician distribution analysis based on specialty and working place. 2011. http://www.tma.tw/stats/stats18.asp. Accessed 12 Nov 2016 